\title{
Current perspectives of cancer-associated fibroblast in therapeutic resistance: potential mechanism and future strategy
}

\author{
Dhruba Kadel • Yu Zhang • Hao-Ran Sun • Yue Zhao • \\ Qiong-Zhu Dong • Lun-xiu Qin
}

Received: 12 September 2018 / Revised: 15 December 2018 / Accepted: 3 January 2019/Published online: 24 January 2019

(C) The Author(s) 2019

\begin{abstract}
The goal of cancer eradication has been overshadowed despite the continuous improvement in research and generation of novel cancer therapeutic drugs. One of the undeniable existing problems is drug resistance due to which the paradigm of killing all cancer cells is ineffective. Tumor microenvironment plays a crucial role in inducing drug resistance besides cancer development and progression. Recently, many efforts have been devoted to understand the role of tumor microenvironment in cancer drug resistance as it provides the shelter, nutrition, and paracrine niche for cancer cells. Cancer-associated fibroblasts (CAFs), one major component of tumor microenvironment, reside in symbiotic relationship with cancer cells, supporting them to survive from cancer drugs. The present review summarizes the recent understandings in the role of CAFs in drug resistance in various tumors. Acknowledging the fact that drug resistance depends not only
\end{abstract}

D. Kadel · Y. Zhang · H.-R. Sun · Y. Zhao • Q.-Z. Dong • L.-X. Qin $(\bowtie)$

Department of General Surgery, Huashan Hospital \& Cancer Metastasis Institute, Fudan University, 12 Urumqi Road (M), Shanghai 200040, China

e-mail: qinlx@fudan.edu.cn

D. Kadel · Y. Zhang · H.-R. Sun • Y. Zhao • Q.-Z. Dong • L.-X. Qin

Cancer Metastasis institute, Fudan University, Shanghai 200040, China

Q.-Z. Dong $(\bowtie) \cdot$ L.-X. Qin

Institute of Biomedical Sciences, Fudan University, 131 Dong An

Road, Shanghai 200032, China

e-mail: qzhdong@fudan.edu.cn upon cancer cells but also upon the microenvironment niche could guide us to formulate novel cancer drugs and provide the optimal cancer treatment.

Keywords Cancer-associated fibroblast · Drug resistance

\section{Introduction}

Various studies have already identified that the nature of tumor does depend not only upon the malignant cancerous cells themselves but also to their microenvironment components (Kalluri 2003). The constituents of tumor microenvironment provide the shelter as well as paracrine niche for cancer cells that fuel the neoplastic growth. It functions as safeguard to tumor cells either by providing the mechanical support or secreting various factors evading the therapeutic effect. The role of microenvironment in promoting tumor growth and metastasis has been studied to some extent in various cancers (Kalluri and Zeisberg 2006; Li et al. 2007; Tlsty and Coussens 2006) but its role in anti-cancer therapeutic resistance is still poorly understood (Shekhar et al. 2007; McMillin et al. 2010; Wang et al. 2009). Tumor microenvironment comprised of both pro-tumorigenic and anti-tumorigenic components such as stromal cells (normal fibroblasts, cancer-associated fibroblast (CAFs), immune inflammatory cells, endothelial cells, pericytes, bone marrow-derived cells, etc.), structural elements of extracellular matrix (ECM), and soluble factors (such as cytokines, growth factors) (Li 
et al. 2007; Tlsty and Coussens 2006; Quail and Joyce 2013). Recent researches have suggested that these elements interact with tumor cells as well as with each other forming a complex crosstalk network and create either tumor-prone or tumor-suppressive microenvironment, although the involved molecular mechanism is not well understood (Quail and Joyce 2013; Grivennikov et al. 2010; Palucka and Coussens 2016).

CAFs constitute major proportion of non-neoplastic stromal compartment in various human tumors. Various researches have suggested that they are capable of modulating tumor cells by forming the communication network with cancer cells or with other elements and hence susceptible to cancer drug resistance (Orimo and Weinberg 2006; Mueller and Fusenig 2004). So, focusing on both cancer cells and CAFs might provide some new hints for cancer treatment. Here we review the role of CAFs in cancer drug resistance, underlying molecular mechanisms as well as the approached strategies to overcome the potential resistance induced by CAFs.

\section{Origin and markers of CAFs}

CAFs should be considered as the structural and functional alteration rather than cell type variation. Under the various intrinsic or extrinsic influential factors, structural and functional modifications on progenitor cells occur, which, to our current knowledge, are known as CAFs. The progenitor states are transformed to CAFs during the tumor progression, and some of the wellknown progenitors are resident fibroblast and immune cells (Kojima et al. 2010; Erez et al. 2010), bone marrow-derived mesenchymal stem cells (Mishra et al. 2008; Quante et al. 2011; Spaeth et al. 2009; Jeon et al. 2008; Direkze et al. 2004), epithelial cells (Kalluri and Neilson 2003), endothelial cells (Zeisberg et al. 2007), hepatic stellate cells (Yin and Evason 2013), and pancreatic stellate cells (Jaster 2004). Cancerous cells attract bone marrow-derived MSCs to the tumor microenvironment and convert them into CAF-like myofibroblastic phenotype (Mishra et al. 2008; Bergfeld and Declerck 2010). These structurally altered CAFs, which formerly recognized as MSCs, then support tumor cell survival and angiogenesis, possess immunomodulatory function, and lead to drug resistance (Bergfeld and Declerck 2010). Moreover, the well-known resident fibroblasts of pancreas, pancreatic stellate cells, exhibit vitamin A containing lipid droplets in its quiescent state. Once communicated with tumor cells become activated and loose the vitamin A reserving potential, which then display contractile and secretory phenotype. The secretory function of these activated pancreatic stellate cells favors tumor survival (McCarroll et al. 2006).

CAFs are predominantly composed of activated fibroblast, but also with less amount of non-activated fibroblast (Shimoda et al. 2010; Hanahan and Coussens 2012). The activated fibroblast population in CAFs is identified by their expression of specific markers such as $\alpha$-smooth muscle actin ( $\alpha$-SMA), vimentin, desmin, fibroblast activation protein (FAP) (Mueller and Fusenig 2004), fibroblast specific protein (FSP) (Strutz et al. 1995), platelet-derived growth factor receptor (PDGFR) (Pietras et al. 2003), secreted protein acidic and rich in cystein (SPARC), chondroitin sulfate proteoglycan (Sugimoto et al. 2006), prolyl-4 hydroxylase (Kojima et al. 2010), periostin (Malanchi et al. 2012), integrin alpha 11 (Zeltz and Gullberg 2016), and tenascin C (De Wever et al. 2004), where the expression of these markers varies from one cell to another, suggesting the existence of heterogenic population of CAFs. Among these markers, $\alpha$-SMA showed large labeling pattern and has long been accepted as the most reliable marker for identifying activated fibroblast in CAFs (Sugimoto et al. 2006). On the other hand, progenitor states lack $\alpha$-SMA expression and are transformed to $\alpha$-SMA-positive CAFs via cancer cellderived growth factors such as transforming growth factor- $\beta$ (TGF- $\beta$ ) (Orimo et al. 2005), platelet-derived growth factor (PDGF) and fibroblast growth factor-2 (FGF-2) (Elenbaas and Weinberg 2001), Wnt7a (Avgustinova et al. 2016), sonic hedgehog (Shh) (Bailey et al. 2008), and exosomes (Paggetti et al. 2015; Webber et al. 2015). In contrast, there is evidence that leukemia inhibitory factor (LIF), a member of the interleukin-6 (IL-6) pro-inflammatory cytokine family, can transform progenitor state to pro-invasive fibroblast independently of $\alpha$-SMA expression (Albrengues et al. 2014).

Thus, the progenitor and quiescent precursor of CAFs contributes favorable tumor microenvironment to some extent for tumor survival when acquires phenotypic variation (Fig. 1). The tumor-promoting properties of CAFs such as proliferation, angiogenesis, invasion, and metastasis are regulated by various signaling pathways that include stromal cell-derived factor-1 (SDF$1)-[\mathrm{C}-\mathrm{X}-\mathrm{C}]$ chemokine receptor-4 (CXCR4) and TGF- $\beta$-Smad2/3 (Kojima et al. 2010), JAK1/STAT3 (Albrengues et al. 2014; Sanz-Moreno et al. 2011; 
Albrengues et al. 2015), interleukin-1 $\beta$ (IL-1 $\beta$ )-nuclear factor kappa B (NF-k $\beta$ ) (Erez et al. 2010), PDGFPDGFR (Elenbaas and Weinberg 2001; Shao et al. 2000), Yes-associated protein/Tafazzin (YAP/TAZ) (Dupont et al. 2011; Calvo et al. 2013), ShhSmoothened (Smo) (Bailey et al. 2008), P62-mTORC1 (Valencia et al. 2014), loss of Timp gene (Khokha et al. 2013), and global hypomethylation of genomic DNA (Hu et al. 2005; Jiang et al. 2008).

\section{CAFs in tumor suppression}

Even though pro-tumorigenic properties of CAFs have been revealed by numerous studies, the inefficacy of stromal targeted therapies in several preclinical studies have raised the doubt in clinical application. A significant number of possible explanations have been put forwarded, and the interesting but insufficient evidences suggested the possibility of tumor-suppressive function of CAFs. The long-term administration of hedgehog $(\mathrm{Hh})$ inhibitor in genetically engineered pancreatic ductal adenocarcinoma (PDAC) and chemically induced bladder cancer mice model showed reduction in stromal contents consequently promoting tumor growth and malignancy, which indicated stromal cells function as tumor suppression (Rhim et al. 2014; Shin et al. 2014). This finding was also supported by other study showing that the depletion of CAFs resulted in suppressed immune surveillance with increased CD4+FoxP3+ Tregs and led to invasive, poorly differentiated, and enhanced stemness of cancer cells experimented in PDAC mice model (Özdemir et al. 2014). Contradictory to many previous studies, a recent study verified that presence of higher number of FAP+ CAFs (> 100/high-power field) in PDAC stromal cells is associated with prolonged survival (Park et al. 2017). Similarly, the other study revealed the mechanism of CAFs in tumor suppression via Slit2-Robo1-mediated suppression of $\mathrm{PI} 3 \mathrm{~K} / \mathrm{AKT} / \beta$-catenin pathway in breast cancer cell lines (Chang et al. 2012). Another example of tumorsuppressive function of CAFs is that the deletion of nuclear factor kappa $B$ kinase subunit $\beta$ (IKK $\beta$ ) in murine model of colitis-associated tumorigenesis resulted in neoangiogenesis and tumor progression showing the tumor-suppressive role of IKK $\beta$ (Pallangyo et al. 2015); however, opposite results were shown in the same model by other research group (Koliaraki et al. 2015). The contradictory results observed in two different studies with similar model could be explained as (1)
IKK $\beta$ was deleted in type-I-collagen fibroblast by the first research group and in type-VI-collagen fibroblast by the latter one; (2) besides genetic background of the mice, timing of IKK $\beta$ deletion and (3) existence of heterogeneous fibroblast subpopulation in tumor stroma might play a role in different findings (Wagner 2016).

Inconsistent outcomes of CAFs in pro- and antitumorigenicity might be due to its wide sources as well as diversity in its secretory function and establishing different communication network with tumor cells. The origin of CAFs determining its nature could be illustrated as CD271+. Pancreatic stellate cells showed anti-tumorigenic properties (Fujiwara et al. 2012) while $\mathrm{CD} 10+$ pancreatic stellate cells were identified as protumorigenic nature (Ikenaga et al. 2010). Whereas the secretory function characterizing CAFs was also shown by various studies. One study verified the dual function of periostin secreted by CAFs as its slight overexpression significantly reduced epithelial-mesenchymal transition (EMT), whereas higher overexpression enhanced EMT in human pancreatic cells (Kanno et al. 2008). Moreover, one of the major ECM factors secreted by CAFs is hyaluronan (HA), whose role in cancer has been studied well. Large number of clinical analysis have shown that tumor progression and poor outcome in various cancers is associated with higher accumulation of HA either in stroma or in tumor parenchyma (Wu et al. 2017; Turley et al. 2016; Sato et al. 2016; Chanmee et al. 2016; Bourguignon et al. 2017). Studies have shown that CAFs secreted HA played crucial role in migratory interaction of CAFs and tumor cells. So, the mitogenic properties of highly motile CAFs are based on HA concentration (Costea et al. 2013). Apart from promoting CAF motility, a major susceptible factor for cancer supporting role of HA might be its participation in EMT program. Studies have shown that HA accumulation either by HAS3 overexpression or by hypoxia inducible factor- $1 \alpha$ (HIF-1 $\alpha$ ) leads to induction of EMT (Zhang et al. 2013; Misra et al. 2008; Kultti et al. 2014; Gao et al. 2005). However, some recent studies have recognized HA as tumor-suppressing stromal component (Bohaumilitzky et al. 2017; Fisher 2015; Triggs-Raine 2015; Tian et al. 2013). The cancer resistance properties of HA were first noted in naked rat mole, where authors observed that naked rat mole fibroblasts secreted extremely high molecular mass HA, cells possessed higher affinity to HA signaling, and HAdegrading enzyme showed less activities (Tian et al. 2013). The elaborative study pointed that high 


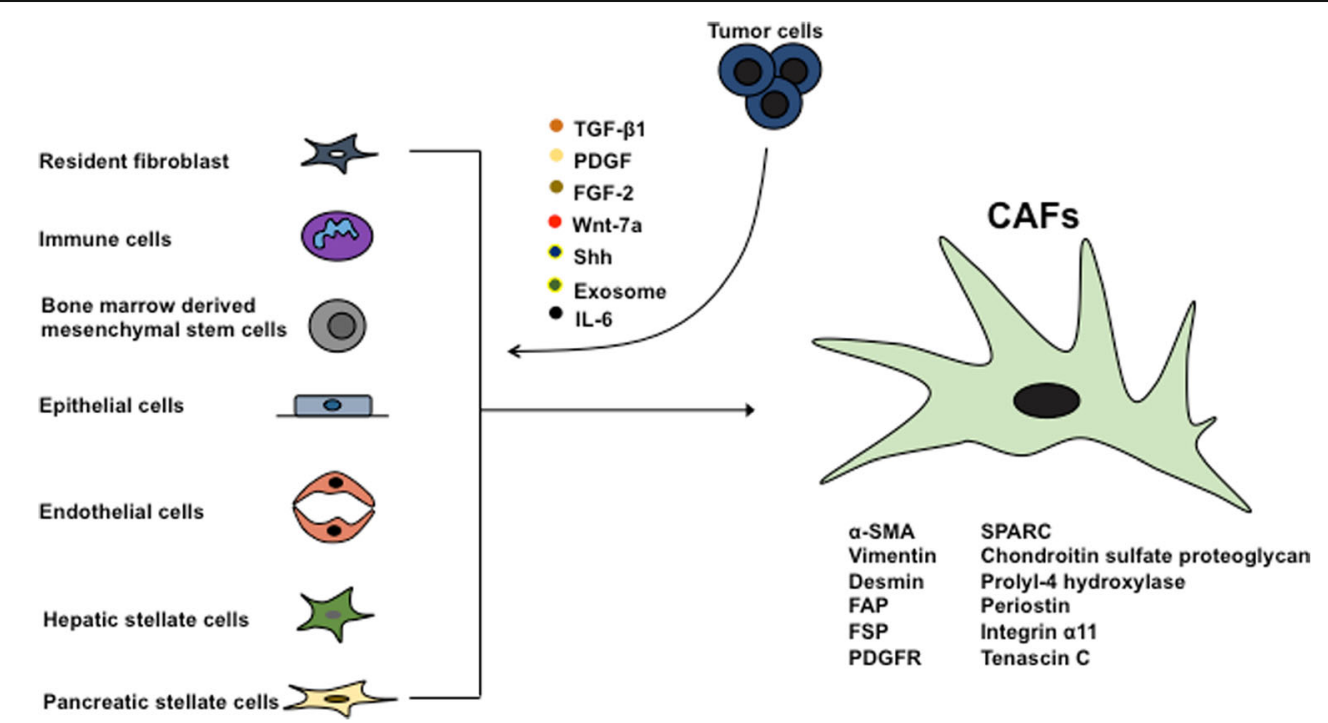

Fig. 1 Heterogeneous origin of CAFs and its markers. Cancerassociated fibroblasts are originated from various sources, which are in quiescent state and convert into CAFs after communicating

molecular HA has ability to hypersensitize cells to contact inhibition and stimulate p16 (INK4a locus) expression resulting in cell cycle arrest (Tian et al. 2015). Consistent to this, another study revealed that excess HA production was found to be associated with inhibition to G1-S transition in cell cycle rather than acting as tumorigenesis (Bharadwaj et al. 2011). Supporting to this, hyaluronidase showed tumor growth suppression and facilitated cancer drug treatment (Wong et al. 2017; Melanie and Simpson 2008). These observations can conclude that high-weight HA with less tendency for degradation could provide the cancer resistance properties.

The dynamic nature of CAFs during the cancer progression focuses on further need for discussion to recognize it as friend or foe. In author's view, categorizing the specific subpopulation of CAFs would more precisely characterize their role in cancer environment. A study identified two distinct subpopulations of CAFs as inflammatory fibroblast (iCAFs) and myofibroblast (myCAFs), where they observed that myCAFs lack tumor-promoting chemokines and cytokines (Öhlund et al. 2017). Furthermore, another study also identified the two distinct subpopulation of stromal types based on gene expression as normal (expressing high CAF markers such as $\alpha$-SMA, vimentin, and desmin) and activated (expressing more gene-related macrophage) stroma (Moffitt et al. 2015), as shown in Fig. 2. This can hypothesize that normal stromal cell can be with malignant cells and express different markers differentiating from its progenitor state

considered as good stroma and may show tumorsuppressive function. Combining the aforementioned studies, a detail study can be carried out to identify if good stroma only secretes high molecular mass HA. Thus, it alarms the preservation of tumor-suppressing stromal cells when generating stromal-targeted therapies for cancer treatment.

\section{Roles of CAFs in drug resistance}

Drug resistance via revascularization and reactivating MAPK and Akt

One of the problems in eradication of cancer is the drug resistance. Tumor cells follow different paths to become resistance to cancer treatment depending upon the intrinsic properties or external stimuli from microenvironment (Hata et al. 2016). Many researchers are focusing on various external stimuli from tumor microenvironment inducing drug resistance. Numerous studies have tried to explore the role of stromal cells, especially fibroblasts and CAFs in drug resistance in different tumors (Straussman et al. 2012; Mao et al. 2013; Paraiso and Smalley 2013). Majority of studies have proven that the secretory function of CAFs, which establishes the crosstalk with tumor cells, is responsible for drug resistance. One study revealed that CAFs extracted from anti-VEGF resistance murine lymphoma 
Fig. 2 The dual nature of CAFs. Two distinct subpopulation of CAFs that are based on its secretory function and expression markers and play the subsequent role in tumor microenvironment

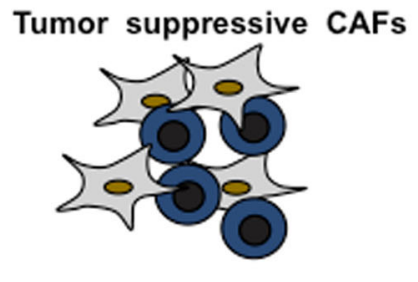

$\alpha$-SMA,
vimentin
desmin
CD271
FAP
HA
myCAFs
Tumor promoting CAFs

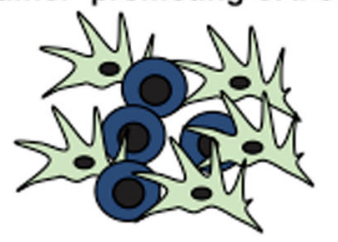

CD10

HA

Genes related macrophage iCAFs cell line (EL4) could effectively resist the anti-VEGF therapy in otherwise sensitive murine myeloma cell line (TIB6) via platelet-derived growth factor-C (PDGF-C) mediation (Crawford et al. 2009). Authors observed the upregulation of PDGF-C in CAFs and hence inducing the revascularization, which ultimately led to antiangiogenic therapy resistance. Most of the patients treated with anti-angiogenesis such as sorafenib, sunitinib, and bevacizumab appeared to be low/no response after certain period of treatment with only modest benefit in clinical outcomes (Jayson et al. 2016). This could suggest that there might be morphologic and functional changes of CAFs after exposure to anti-angiogenic treatment recreating the angiogenic environment and becoming refractory to drug therapy. Another experiment showed that stromal fibroblast could induce resistance to epidermal growth factor receptor (EGFR) tyrosine kinase inhibitors via hepatocyte growth factor (HGF) mediated crosstalk between tumor cells and stromal cells in lung cancer (Wang et al. 2009). Furthermore, the study carried out in tumor microenvironment induced drug resistance showed that various BRAF mutated melanoma and ERBB2+ breast cancer cell lines when co-cultured with different fibroblasts affected the sensitivity to vemurafenib and lapatinib, respectively, via HGF/c-MET pathway (Straussman et al. 2012). This result was also supported by another study revealing that most cancer cells could be rescued from drug by simply exposing to one or more receptor tyrosine kinase (RTK) ligands (Wilson et al. 2012). It is well known that HGF/ c-MET signaling activates MAPK cascades enhancing cancer cell proliferation and Akt cascades increasing the anti-apoptotic effects, which could eventually increase the drug tolerance capacity in various cancers (Xiao et al. 2001).
Drug resistance in hypoxic environment

Many studies have pointed out the ability of CAFs to modulate drug sensitivity in hypoxic environment. CAFs secrete different angiogenic factors and prominent one being the VEGF, whose production is even increased in hypoxic state (Beckermann et al. 2008; Masamune et al. 2008). However, a recently published study verified that endothelial cell sprouting was observed more with hypoxic CAFs even upon blocking VEGFA, which indicated presence of other angiogenic agent (Kugeratski et al. 2016). Further study on proteomic analysis of hypoxic CAFs revealed the upregulation of proteins related to glycolysis and downregulation of proteins related to mitochondrial metabolism. A detail study is needed to unveil the other associated factors responsible for angiogenesis. Furthermore, hypoxia stimulated pancreatic fibroblast and promoted angiogenesis via expression of VEGF receptors, angiopoetin- 1 and Tie-2, and these pancreatic fibroblasts induced pancreatic cancer cell motility via IGF1/ IGF1R signaling (Masamune et al. 2008; Hirakawa et al. 2016).

Acidic environment created by hypoxia produces the lactic acid within ECM without changing the intracellular PH that blocks the accumulation of drugs within the cancer cells (Harrison and Blackwell 2004; Vukovic and Tannock 1997). In some drugs such as doxorubicin, which is oxygen-dependent, effect is obviously reduced in hypoxic environment (Harrison and Blackwell 2004). Hypoxic environment drives the hypoxia-inducible factor 1 (HIF-1) to upregulate the drug resistance genes encoded ATP-binding cassette transporters (ABC) (Wartenberg et al. 2003). Proteins of ABC family have been well studied and their functions are well known, 
which play a major role in drug resistance through multiple functions including efflux of drug from cancer cells (Fletcher et al. 2010). Moreover, as mentioned previously, HIF- $1 \alpha$ signaling is associated with HA accumulation promoting EMT and ultimately to drug resistance (Zhang et al. 2013; Gao et al. 2005). A study pointed out the possible way to overcome this by depleting HA accumulation, which inhibits HIF- $1 \alpha$-snail signaling and suppresses EMT (Kultti et al. 2014). The role of hypoxia in generating the tumor drug resistance has been well reviewed and suggested to target hypoxia in treating cancer to get the better outcome (Wilson and Hay 2011). These studies provided the sufficient proofs that the regulation of drug sensitivity of cancer cells by CAFs, especially in hypoxic environment, is also inevitable. However, hypoxic CAFs secreted key player to induce the resistance may not have been characterized yet and continuous effort is needed to unravel it.

Contradictory to this, a study reported that the prolonged hypoxia can cause the deactivation of CAFs and diminishes the role of CAFs (Madsen et al. 2015). A detail study is needed to clarify it more.

Drug resistance by secreting soluble factors

As mentioned earlier, tumor microenvironment, notably fibroblasts and CAFs, elicits drug resistance via secretion of various soluble factors. Among these proteins, Wnt family member wingless-type MMTV integration site family member 16B (WNT16B), which is regulated by NF- $K \beta$ after DNA damage, activates the canonical Wnt program in tumor cells and induces cytotoxic chemotherapy resistance in prostate cancer (Sun et al. 2012). They showed that WNT16B was upregulated in chemotherapy administered prostate, breast, and ovarian cancers and verified both in vitro and in vivo that WNT16B secreted by fibroblast was responsible for inhibiting the chemotherapy-induced apoptosis. Another study revealed that fibroblasts secreted frizzledrelated protein 2 (SERP2) after genotoxic treatment could augment $\beta$-catenin activities initiated by WNT16B and enhanced chemotherapy resistance in prostate cancer (Sun et al. 2016). Moreover, other proteins, cytokines and chemokines, secreted by CAFs can switch the tumor cells genotypically and phenotypically exhibiting the drug resistance properties. Interleukin17A (IL-17A) secreted by chemotherapy-treated human CAFs promoted the colorectal cancer initiating cell (CIC) self-renewal and tumor growth displaying the conventional chemotherapy resistance features (Lotti et al. 2013). Authors noted the significant increase of CAFs after the chemotherapy, which further suggested the possibilities of alteration of CAF features induced by various drugs. This speculation was supported by another study showing that initially well responded BRAF-mutant melanoma cells to PLX4720 became tolerant after certain period of treatment by reactivating ERK/MAPK in the areas of high stromal density (Hirata et al. 2015). This is due to activation of stromal fibroblast, elevation of matrix production, and remodeling leading to elevated integrin $\beta 1 / \mathrm{FAK} / \mathrm{Src}$ signaling in melanoma cells associated with BRAF inhibitor, PLX4720. These findings suggested that chemotherapy or radiotherapy could enhance the secretions of stromal derived factors besides killing cancer cells, and provide the survival benefit to cancer cells and resulting in drug resistance. This concept was also supported by other two independent studies (Acharyya et al. 2012; Nakasone et al. 2012). Therefore, approaches to curative treatment to cancer became likely insufficient due to avoiding the fact of therapy-derived functional switch of stromal cells.

Drug resistance via stromal modification

Desmoplastic stroma also could sufficiently hinder the drug delivery by inducing vascular collapse. A study in PDAC mouse model refractory to gemcitabine was observed poor vascularization with poor perfusion, but when co-administered with IPI-926, hedgehog cellular signaling inhibitor, significantly increased both vascularization and perfusion by reducing tumor-associated stromal tissue (Olive et al. 2010). Moreover, HA was also found to be responsible for generating high interstitial fluid pressure (IFP) inducing vascular collapse and acted as barrier for drug perfusion and diffusion in PDAC mice model (Provenzano et al. 2012). Researchers found that enzymatic breakdown of stromal hyaluronic acid before administration of cancer drug therapy resulted in remodeling of microenvironment, normalized IFP, and reestablished the microvascular structure, which ultimately enhanced the therapeutic effect. This study was further supported by the research published in following year, observed that stromal hyaluronic acid depletion by PEGylated recombinant PH20 hyaluronidase (PEGPH20) tested in PDAC mice model could successively increase the intratumoral delivery of chemotherapeutic drugs, doxorubicin and 
gemcitabine (Jacobetz et al. 2013). Apart from HA, CAFs also modulated the drug delivery in cancer cells via mechanism of PDGFR involved increased IFP (Heldin et al. 2004). The role of PDGFR in drug resistance by increasing IFP have been supported by other independently published data showing that PDGFR inhibitor could reduce the vascular intercellular pressure and facilitate the drug transport into the cancer cells (Pietras et al. 2003; Östman and Heldin 2007). These findings suggested that desmoplastic stroma and hypoperfused tumor generated by CAFs could hinder the effective drug perfusion leading to drug resistance. Moreover, matrix remodeling by CAFs can form the chemoprotective niche and hence blocks the effective delivery of chemotherapeutic drugs to the cancer cells via cell adhesion-mediated drug resistance (CAM-DR), contributing its role in evading cancer cells to treatment (Meads et al. 2009). Researchers have described the presence of number of molecules on the cell membrane of CAFs such as cell surface proteoglycans, integrin, and non-integrin collagen receptors, which participate in cell adhesion mechanism that protect cancer cells from drug-induced apoptosis (Zeltz and Gullberg 2016; Multhaupt et al. 2016). One study explained the role of CAM-DR on modulation of cancer cell adhesion on ECM in multiple myeloma showing that the adhesion resulted in increased p27kip1 levels that associated with cell cycle arrest and resistance to melphalan (Hazlehurst and Dalton 2001). The role of focal adhesion molecule including integrins, integrin-associated proteins, and growth factor receptors have been highlighted in recently reviewed article (Eke and Cordes 2015). These findings suggested that cell-matrix interaction caused reorganization of cytoskeleton and induced the multiple signaling pathways, which was sufficient to cause drug resistance. However, the experiment on mouse model of pancreatic cancer showed that desmoplastic response and fibrosis could be restored by the inhibition of HhSmo pathway and permitted the well distribution of drugs in the cancer cells (Olive et al. 2009). So, there is still dim hope to overcome the cancer drug resistance due to stromal modification, and continue study to understand the mechanism in detail is needed.

\section{Role in endocrine treatment resistance}

The endocrine treatment resistance is widely observed even in estrogen receptor-positive (ER+) breast cancers. A research performed in ER+ MCF-7 cells showed that
CAF was the source of tamoxifen and fulvestrant resistance and also protected cancer cells from doxorubicin and PARP inhibitor (Martinez-outschoorn et al. 2011). They found that tamoxifen promoted the upregulation of TP53-induced glycolysis and apoptosis regulator (TIGAR), P53 regulated gene that can inhibit glycolysis, autophagy, and apoptosis and reduces ROS generation, in CAF co-cultured MCF-7 cells enhancing the oxidative mitochondrial metabolism, which provided the survival benefit to cancer cells. The inhibition of mitochondrial activities by metformin or arsenic trioxide led to increase in glucose uptake by mitochondria resulting in metabolic imbalance between cancer cells and CAFs that resensitized tamoxifen treatment. Another independent research on MCF-7 cells showed that soluble factors secreted by fibroblast rescued the tumor cells from tamoxifen by the mechanisms that involved EGFR and matrix metalloproteinases (Pontiggia et al. 2012)]. They verified that stromal factors as the modulators of ER activity showing that fibroblasts were able to phosphorylate ER at serine-118. In contrast to this, a research performed by Shekhar et al. showed that sensitive premalignant EIII8 and tumorigenic MCF-7 cells when cocultured with the fibroblast derived from ER-/progesterone receptor (PR)- human breast tumors conferred the tamoxifen resistance independently of EGFR (Shekhar et al. 2007). They observed the noncorrelation between tamoxifen resistance and level of EGFR or phospho-EGFR and endocrine sensitivity. However, some studies have concluded that the in vitro EGFR sensitivity in neck squamous cell carcinoma and lung cancer is modulated by co-cultured fibroblast, indicating that the role of fibroblast in cancer drug resistance via EGFR mechanism should not be neglected (Wang et al. 2009; Johansson et al. 2012).

Role in immunotherapy resistance

The hope to treat cancer patients is becoming dim with the increased report of immunotherapy resistance. Immune system is complex to understand but various researches have tried to explore the role of immune system in cancer development and put forward the idea of dual function of immune cells, pro- and anti-tumor progression (DeNardo et al. 2010). In fact, the role of microenvironment components in tumor promotion or suppression somehow depends on the nature of infiltrated immune cells in the microenvironment (OstrandRosenberg 2008). Tumor microenvironment is 
infiltrated by various immune cells in response to inflammation and secret growth factors such as TGF, FGF, VEGF, and some members of the interleukin family, which can act as driving force for fibroblast activation (De Visser et al. 2006; Calvo and Sahai 2011). In the other hand, fibroblasts are also able to modulate the tumor immune system. The role of fibroblast in altering the immune-controlled tumor growth was described in transgenic Lewis lung carcinoma and subcutaneous PDAC mouse model, where it was observed that depletion of FAP-expressing cells enhanced the hypoxic necrosis of both tumor and stromal cells by a process involving interferon- $\gamma($ IFN- $\gamma$ ) and tumor necrosis factor- $\alpha$ (TNF- $\alpha)$ (Kraman et al. 2010). This result was further supported by another research showing FAP-expressing CAF as the main source for the resistance of two immunological checkpoint antagonists: anti-cytotoxic T lymphocyte-associated protein-4 $(\alpha-$ CTLA4) and $\alpha$-programmed cell death ligand $1(\alpha-$ PD-L1), in PDAC mice model (Feig et al. 2013). The failure of these checkpoint inhibitors was driven by CAF-secreted chemokine [C-X-C motif] ligand 12 (CXCL12). Administration of CXCL12 receptor inhibitor enhanced the $\mathrm{T}$ cell accumulation at cancer site and acted synergistically to those immunological checkpoint antagonists. These research findings alarmed that CAFs are consistently supporting cancer cells to evade a potential curative therapy of cancer, immunotherapy, requiring to further explore the function of CAFs.

\section{Drug resistance via epigenetic modification}

Various researches have pointed that the epigenetic modification of cancer cells induced by CAFs is responsible for drug resistance. Some studies have reported that DNA methylation status of stroma associated with the methylation profile of adjacent malignant cells $(\mathrm{Hu}$ et al. 2005; Hanson et al. 2006). Consistent to this, soluble factors secreted by CAFs upregulated wide patterns of genes ( 372 genes) in breast cancer cells that are epigenetically modified by DNA hypermethylation at transcription start site and shore regions. This effect was silenced on inhibition of DNA methylation (Mathot et al. 2017). This was further supported by another research showing that CAF secreted factors were responsible for combinatorial DNA hyper/hypomethylation, which induced EMT and stemness phenotype in prostate cancer cell (Pistore et al. 2017). They observed that methylation was DNM3TA dependent and its knockdown prevented EMT program. Many researches have already verified that EMT and stemness were also one major contributory factor for cancer drug resistance. Furthermore, a study revealed that EMT and metastasis were promoted by TGF- $\beta$ secreted by CAFs, which catalyzed the global DNA hypermethylation changes in epithelial ovarian cancer cell (Cardenas et al. 2014). Authors further observed that DNMT inhibitor knock down the hypermethylation and EMT effect.

Similarly, few studies are available showing that posttranscriptional histone modification of cancerassociated CAFs caused cancer-promoting behavior. A study showed that expression of both the histone mark H3K27me3 and enhancer of zeste homolog 2 (EZH2) was decreased in breast CAFs and promoted cancer invasion by overexpression of thrombospondin type 1 (Bracken et al. 2006; Tyan et al. 2012). Epigenetic modification on cancer cells induced by CAFs causing drug resistance is outgrowing topic, and a detailed study is needed to address the drug resistance issues. In our knowledge, a better result could be expected by combination of demethylating agent and targeting agent to CAF secreted factor responsible for epigenetic modification.

\section{Anti-fibroblastic therapies}

Many studies are available examining the antifibroblastic therapies in cancer treatment. Analyzing the various related published research work, the current focus being either to deplete the stroma or inactivate CAFs. The most potential one is targeting to HA, stromal component secreted by CAFs. A phase Ib clinical study showed that doxorubicin increased median progression-free survival and overall survival when applied in combination with PEGPH20 (7.2 and 13 months in high HA and 3.5 and 5.7 months in low HA tissue level, respectively) (Hingorani et al. 2016). This was in consistent with another phase II study, which showed that nab-paclitaxel/gemcitabin in combination with PEGPH20 obviously increased progression-free survival in patients with metastatic PDAC as compared to nabpaclitaxel/gemcitabine [hazard ratio (HR) $0.73, P=$ 0.049 and in patient with high HA tumors HR 0.51 , $P=0.048$ ] (Hingorani et al. 2018)]. As mentioned previously, PEGPH20 degraded HA and nab-paclitaxel also believed to be depleting agent of stromal component (Jacobetz et al. 2013; Von Hoff et al. 2013). Similarly, a recently published article showed the increased 
concentration of carboxymethyl cellulose docetaxel nanoparticle (CellaxTM-DTX) at SMA CAFs degrading the stromal component. Whereas, the latest studies have also verified the possibility of reverting activated CAFs. A study showed that the anti-cancer compound minnelide, water-soluble pro-drug of triptolide extracted from Chinese plant Tripterygium wilfordii, disrupted TGF- $\beta$ signaling and hence reverted activated CAFs to quiescent form by decreasing $\alpha$-SMA expression, reducing ECM secretion, and increasing vitamin A-containing lipid droplets (Dauer et al. 2018)]. Moreover, another study also supported the strategy to revert activated CAFs showing that application of all-transretinoic acid (ATRA) promoted the quiescence form of pancreatic stellate cells resulting in Wnt-beta-catenin signaling and reduced tumor progression (Froeling et al. 2011).

Thus, newly recognized CAFs targeted molecules like PEGPH20, nab-paclitaxel, CellaxTM-DTX, minnelide, and ATRA could be regarded as the novel cancer therapeutic agent in the modern era. However, it should also be noted that the various researches have pointed that simple depletion of stroma could promote spreading of cancer cells rather than only facilitating drug delivery. A study reported that simple blocking of serum amyloid A1 (SAA1), poor prognostic marker in pancreatic cancer cells, did not inhibit tumor growth and they verified two subtypes: saa3-competent and saa3-null CAFs, which showed pro-tumorigenic and anti-tumorigenic effect, respectively (Djurec et al. 2018). So, in author's view, selective depletion of stroma would provide the better result in cancer treatment.

As mentioned previously, one reason behind the resistance of a new hope of cancer treatment, an immunotherapy, is induced by CAFs. But, dim hope still remains with continuous exploration and understanding its mechanism. CAF-induced resistance of two checkpoint inhibitors ( $\alpha$-CTLA4 and $\alpha$-PD-L1) was blocked by CXCL12 receptor inhibitor (Feig et al. 2013)]. Similarly, Janus Kinase 2 (JAK2) inhibitor, which can modify the stroma, also decreased PD-L1 expression and enhanced the anti-cancer treatment as demonstrated in in vitro cancer cells (Wörmann et al. 2016; Doi et al. 2017)]. Consistent to this, another research showed possible enhancement of anti-PD-L1 treatment via inhibiting the IL-6, a JAK activator (MacE et al. 2018). Hence, all these evidences verify that targeting stroma can enhance the immunotherapy.

\section{Discussion}

Despite the continuous progress in current cancer research and development of novel drugs, the problems against cancer drug resistance were not vanquished. Earlier, great efforts were given to resolve the cancer drug resistance focusing on the properties of cancer cells themselves, but recently, the role of microenvironment in drug resistance becomes the emerging topic for many researchers. Among the microenvironment components, CAFs have been long studied in exploring the mechanism of initiation of cancer, cancer progression, and metastasis (Kalluri and Zeisberg 2006). As discussed previously, CAFs should be regarded as the transitioned state rather than distinct cell type, but instead of knowing progenitors of CAFs, we are still unable to find the distinctive markers that can differentiate between different states. CAFs reside in the microenvironment as symbiotic relationship with cancer cells and provide the shelter, nutrition, and paracrine niche for tumor growth and function as backbone of microenvironment. Breakdown of this correlation is warranted to defeat cancer, and this can be achieved by understanding the structure and function of each of the constituents of microenvironment. Here we have reviewed the role of CAFs, pillar of tumor microenvironment, in drug resistance, and its underlying mechanism and highlighted the feasible way of reversal. As shown in Fig. 3, we have tried to summarize the CAF's contribution in drug resistance by different aspects such as participating in revascularization, immune modulation, ECM remodeling, and providing the alternative pathway for cancer cells to induce drug resistance. Knowing these facts would help in determining the better strategy for the treatment of cancer patients and provides certain guidelines in the generation of next cancer drugs avoiding potential risk of therapy resistance.

Some of the researches have also pointed out the tumor-suppressive function of CAFs, which has been briefed above in this review, and suggested no need to pursue them while treating cancer to get the better outcome. The controversial study published regarding the tumor-suppressive role of CAFs has been discussed in detail in respective segment. But to our knowledge, failure to recognize CAFs as friend or foe is due to (1) unable to identify its specific origin (for, e.g., differences in CD271+ and CD10+ pancreatic stellate cells originated CAFs) (Fujiwara et al. 2012; Ikenaga et al. 2010), (2) inadequate knowledge to characterize its 


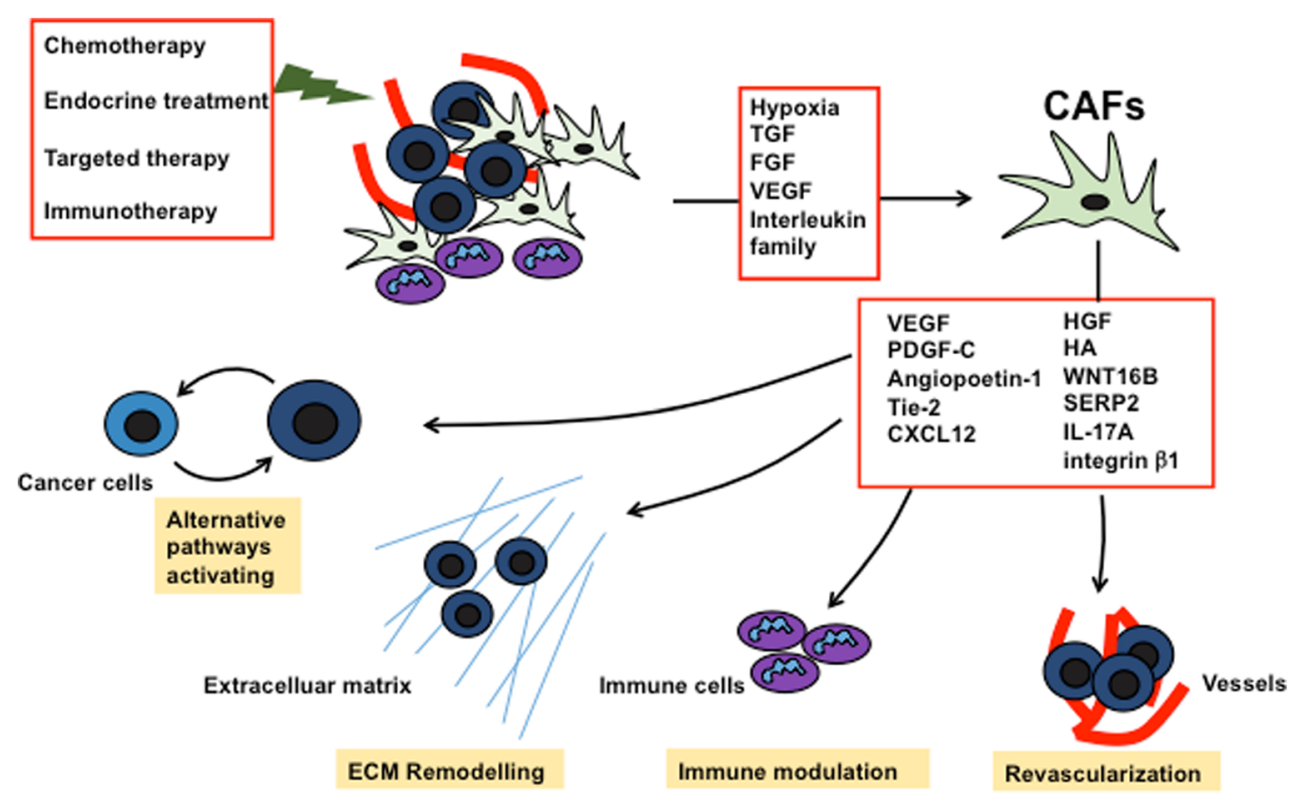

Fig. 3 Roles of CAFs in drug resistance. CAFs play important role in cancer drug resistance via secretion of different factors and modulation of tumor microenvironment resulting reduction of drug efficacy or activation of cancer cells by alternating pathway

secreted factors (for, e.g., different function of CAFs secreted high- and low-weight HA), and (3) improper characterization of CAFs (for, e.g., existence of different subpopulation of CAFs as iCAFs and myCAFs). Moreover, the existence of heterogenic properties of CAFs also keeps us in dilemma in its appropriate characterization, which can be further elaborated as, as described above, CAFs are able to express various markers, and none of the markers are completely overlapped; CAFs' contents are relatively higher in highly dense breast, pancreatic, and prostate cancer while lower contents are detected in brain and renal tumors (Prakash 2016). CAFs are the phenotypic and functional switch from normal stromal cells, also termed as progenitors of CAFs within this review, and study reported that CAFs are much more competent in supporting tumor growth and metastasis than normal stromal fibroblasts (Orimo et al. 2005). One research has pointed out the importance of functional state of stromal cells, where they showed that the stromal signatures were more reliable than whole tissue signatures for predicting the clinical outcome in breast cancer patients (Finak et al. 2008). Drug sensitivity of cancer cells in the presence of CAFs also depends on the cancer types and microenvironment (Sonnenberg et al. 2008). Further study regarding identification and classification of CAFs is needed to better explain these existing problems.
One previous study showed that despite the heterogeneity of CAFs, they are genetically more stable than cancer cells. Therefore, targeting CAFs in cancer treatment would have smaller possibilities to develop drug resistance (Kerbel 1997)]. Recently published data have suggested the strategies to modulate CAFs either by inhibiting the activation pathway of CAFs or by breaking the drug delivery barrier created by CAFs. Preclinical studies showed that inhibiting TGF- $\beta$, angiotensin receptor, and Hedgehog signaling could reduce CAFs and ECM contents and improve the drug delivery (Olive et al. 2009; Liu et al. 2012). Similarly, suppression of CAF mediated secretion of IL- 6 by inhibiting mTOR pathway via somatostatin analogue reversed the chemoresistance in pancreatic tumor (Duluc et al. 2015). Moreover, one recently published article showed that application of micro-RNA (miRNA) was possible in reverting the CAF phenotype to non-CAF phenotype (Kuninty et al. 2016). Detail discussion of targeted stromal therapy has been discussed in this review. To our knowledge, reversing the phenotype of CAFs rather than depleting may provide better solution for drug resistance.

In conclusions, CAFs, the building block of microenvironment, have a crucial role in modulating cancer drug sensitivity and understanding in detail could minimize the existing challenge of drug resistance and direct the future innovation of cancer drug by avoiding or overcoming the drug resistance. 
Financial support statement This research is supported by the National Key Research and Development Program of China (2017YFC1308604 and 2017YFC0908402), the "973" State Key Basic Research Program of China (2014CB542101 and 2013CB910500), National Natural Science Foundation of China (81772563, 81672820, and 81372647), and China National Key Projects for Infectious Disease (2012ZX10002-012).

OpenAccess This article is distributed under the terms of the Creative Commons Attribution 4.0 International License (http:// creativecommons.org/licenses/by/4.0/), which permits unrestricted use, distribution, and reproduction in any medium, provided you give appropriate credit to the original author(s) and the source, provide a link to the Creative Commons license, and indicate if changes were made.

Publisher's note Springer Nature remains neutral with regard to jurisdictional claims in published maps and institutional affiliations.

\section{References}

Acharyya S, Oskarsson T, Vanharanta S, Malladi S, Kim J, Morris $\mathrm{PG}$, et al. A CXCL1 paracrine network links cancer chemoresistance and metastasis. Cell. 2012;150(1):165-78.

Albrengues J, Bourget I, Pons C, Butet V, Hofman P, TartareDeckert $\mathrm{S}$, et al. LIF mediates proinvasive activation of stromal fibroblasts in cancer. Cell Rep. 2014;7(5):1664-78.

Albrengues J, Bertero T, Grasset E, Bonan S, Maiel M, Bourget I, et al. Epigenetic switch drives the conversion of fibroblasts into proinvasive cancer-associated fibroblasts. Nat Commun. 2015;6:10204

Avgustinova A, Iravani M, Robertson D, Fearns A, Gao Q, Klingbeil $\mathrm{P}$, et al. Tumour cell-derived Wnt7a recruits and activates fibroblasts to promote tumour aggressiveness. Nat Commun. 2016;7:10305.

Bailey JM, Swanson BJ, Hamada T, Eggers JP, Singh PK, Caffery $\mathrm{T}$, et al. Sonic hedgehog promotes desmoplasia in pancreatic cancer. Clin Cancer Res. 2008;14(19):5995-6004.

Beckermann BM, Kallifatidis G, Groth A, Frommhold D, Apel A, Mattern J, et al. VEGF expression by mesenchymal stem cells contributes to angiogenesis in pancreatic carcinoma. Br J Cancer. 2008;99(4):622-31.

Bergfeld SA, Declerck YA. Bone marrow-derived mesenchymal stem cells and the tumor microenvironment. 2010:249-61.

Bharadwaj AG, Goodrich NP, McAtee CO, Haferbier K, Oakley GG, Wahl JK, et al. Hyaluronan suppresses prostate tumor cell proliferation through diminished expression of $\mathrm{N}$ cadherin and aberrant growth factor receptor signaling. Exp Cell Res. 2011;317(8):1214-25 Available from: https://doi. org/10.1016/j.yexcr.2011.01.026.

Bohaumilitzky L, Huber A-K, Stork EM, Wengert S, Woelfl F, Boehm H. A trickster in disguise: Hyaluronan's ambivalent roles in the matrix. Front Oncol. 2017;7(October) Available from: http://journal.frontiersin.org/article/10.3389 /fonc.2017.00242/full.

Bourguignon LYW, Earle C, Shiina M. Activation of matrix Hyaluronan-mediated CD44 signaling, epigenetic regulation and chemoresistance in head and neck cancer stem cells. Int J Mol Sci. 2017;18(9):1-14.

Bracken AP, Dietrich N, Pasini D, Hansen KH, Helin K. Genomewide mapping of polycomb target genes unravels their roles in cell fate transitions. Genes Dev. 2006;20(9):1123-36.

Calvo F, Sahai E. Cell communication networks in cancer invasion. Curr Opin Cell Biol. 2011;23(5):621-9.

Calvo F, Ege N, Grande-Garcia A, Hooper S, Jenkins RP, Chaudhry SI, et al. Mechanotransduction and YAPdependent matrix remodelling is required for the generation and maintenance of cancer-associated fibroblasts. Nat Cell Biol. 2013;15(6):637-46.

Cardenas H, Vieth E, Lee J, Segar M, Liu Y, Nephew KP, et al. TGF- $\beta$ induces global changes in DNA methylation during the epithelial-to-mesenchymal transition in ovarian cancer cells. Epigenetics. 2014;9(11):1461-72.

Chang PH, Hwang-Verslues WW, Chang YC, Chen CC, Hsiao M, Jeng YM, et al. Activation of Robol signaling of breast cancer cells by Slit2 from stromal fibroblast restrains tumorigenesis via blocking PI3K/Akt/??-catenin pathway. Cancer Res. 2012;72(18):4652-61.

Chanmee T, Ontong P, Itano N. Hyaluronan: a modulator of the tumor microenvironment. Cancer Lett. 2016;375(1):20-30 Available from: https://doi.org/10.1016/j.canlet.2016.02.031.

Costea DE, Hills A, Osman AH, Thurlow J, Kalna G, Huang X, et al. Identification of two distinct carcinoma-associated fibroblast subtypes with differential tumor-promoting abilities in oral squamous cell carcinoma. Cancer Res. 2013;73(13): 3888-901.

Crawford Y, Kasman I, Yu L, Zhong C, Wu X, Modrusan Z, et al. PDGF-C mediates the Angiogenic and tumorigenic properties of fibroblasts associated with tumors refractory to antiVEGF treatment. Cancer Cell. 2009;15(1):21-34.

Dauer P, Zhao X, Gupta VK, Sharma N, Kesh K, Gnamlin P, et al. Inactivation of cancer-associated-fibroblasts disrupts oncogenic signaling in pancreatic cancer cells and promotes its regression. Cancer Res. 2018;78(5):1321-33.

De Visser KE, Eichten A, Coussens LM. Paradoxical roles of the immune system during cancer development. Nat Rev Cancer. 2006;6(January):24-37.

De Wever O, Nguyen Q-D, Van Hoorde L, Bracke M, Bruyneel E, Gespach $\mathrm{C}$, et al. Tenascin-C and SF/HGF produced by myofibroblasts in vitro provide convergent pro-invasive signals to human colon cancer cells through RhoA and Rac. FASEB J. 2004;18(9):1016-8.

DeNardo DG, Andreu P, Coussens LM. Interactions between lymphocytes and myeloid cells regulate pro-versus anti-tumor immunity. Cancer Metastasis Rev. 2010;29(2):309-16.

Direkze NC, Hodivala-Dilke K, Jeffery R, Hunt T, Poulsom R, Oukrif D, et al. Bone marrow contribution to tumorassociated myofibroblasts and fibroblasts. Cancer Res. 2004;64(23):8492-5.

Djurec M, Graña O, Lee A, Troulé K, Espinet E, Cabras L, et al. $\mathrm{Saa} 3$ is a key mediator of the protumorigenic properties of cancer-associated fibroblasts in pancreatic tumors. Proc Natl Acad Sci. 2018:201717802 Available from: http://www. pnas.org/lookup/doi/10.1073/pnas.1717802115.

Doi T, Ishikawa T, Okayama T, Oka K, Mizushima K, Yasuda T, et al. The JAK/STAT pathway is involved in the upregulation of PD-L1 expression in pancreatic cancer cell lines. Oncol Rep. 2017;37(3):1545-54. 
Duluc C, Moatassim-Billah S, Chalabi-Dchar M, Perraud A, Samain R, Breibach F, et al. Pharmacological targeting of the protein synthesis $\mathrm{mTOR} / 4 \mathrm{E}-\mathrm{BP} 1$ pathway in cancerassociated fibroblasts abrogates pancreatic tumour chemoresistance. EMBO Mol Med. 2015;7(6):735-53.

Dupont S, Morsut L, Aragona M, Enzo E, Giulitti S, Cordenonsi $\mathrm{M}$, et al. Role of YAP/TAZ in mechanotransduction. Nature. 2011;474(7350):179-83.

Eke I, Cordes N. Focal adhesion signaling and therapy resistance in cancer. Semin Cancer Biol. 2015;31:65-75.

Elenbaas B, Weinberg R. Heterotypic signaling between epithelial tumor cells and fibroblasts in carcinoma formation. Exp Cell Res. 2001;264(1):169-84.

Erez N, Truitt M, Olson P, Hanahan D. Cancer-associated fibroblasts are activated in incipient neoplasia to orchestrate tumor-promoting inflammation in an NF-??B-dependent manner. Cancer Cell. 2010;17(2):135-47.

Feig C, Jones JO, Kraman M, Wells RJB, Deonarine A, Chan DS, et al. Targeting CXCL12 from FAP-expressing carcinomaassociated fi broblasts synergizes with anti - PD-L1 immunotherapy in pancreatic cancer. Proc Natl Acad Sci U S A. 2013;110(50):20212-7.

Finak G, Bertos N, Pepin F, Sadekova S, Souleimanova M, Zhao $\mathrm{H}$, et al. Stromal gene expression predicts clinical outcome in breast cancer. Nat Med. 2008;14(5):518-27.

Fisher GJ. Cancer resistance, high molecular weight hyaluronic acid, and longevity. J Cell Commun Signal. 2015;9(1):91-2.

Fletcher JI, Haber M, Henderson MJ, Norris MD. ABC transporters in cancer: more than just drug efflux pumps. Nat Rev Cancer. 2010;10(2):147-56.

Froeling FEM, Feig C, Chelala C, Dobson R, Mein CE, Tuveson $\mathrm{DA}$, et al. Retinoic acid-induced pancreatic stellate cell quiescence reduces paracrine Wnt--catenin signaling to slow tumor progression. Gastroenterology. 2011;141(4):14861497.e14 Available from: https://doi.org/10.1053/j. gastro.2011.06.047.

Fujiwara K, Ohuchida K, Mizumoto K, Shindo K, Eguchi D, Kozono S, et al. CD271+ subpopulation of pancreatic stellate cells correlates with prognosis of pancreatic cancer and is regulated by interaction with cancer cells. PLoS One. 2012;7(12).

Gao F, Okunieff P, Han Z, Ding I, Wang L, Liu W, et al. Hypoxiainduced alterations in hyaluronan and hyaluronidase. Adv Exp Med Biol. 2005;566:249-56.

Grivennikov SI, Greten FR, Karin M. Immunity, inflammation, and cancer. Cell. 2010;140(6):883-99.

Hanahan D, Coussens LM. Accessories to the crime: functions of cells recruited to the tumor microenvironment. Cancer Cell. 2012;21:309-22.

Hanson JA, Gillespie JW, Grover A, Tangrea MA, Chuaqui RF, Emmert-Buck MR, et al. Gene promoter methylation in prostate tumor-associated stromal cells. J Natl Cancer Inst. 2006;98(4):255-61.

Harrison L, Blackwell K. Hypoxia and anemia: factors in decreased sensitivity to radiation therapy and chemotherapy? Oncologist. 2004;9(Suppl 5):31-40.

Hata AN, Niederst MJ, Archibald HL, Gomez-Caraballo M, Siddiqui FM, Mulvey HE, et al. Tumor cells can follow distinct evolutionary paths to become resistant to epidermal growth factor receptor inhibition. Nat Med. 2016;22(3): 262-9.
Hazlehurst LA, Dalton WS. Mechanisms associated with cell adhesion mediated drug resistance (CAM-DR) in hematopoietic malignancies. Cancer Metastasis Rev. 2001;20(12):43-50.

Heldin C-H, Rubin K, Pietras K, Ostman A. High interstitial fluid pressure - an obstacle in cancer therapy. Nat Rev Cancer. 2004;4(10):806-13.

Hingorani SR, Harris WP, Beck JT, Berdov BA, Wagner SA, Pshevlotsky EM, et al. Phase Ib study of PEGylated recombinant human hyaluronidase and gemcitabine in patients with advanced pancreatic cancer. Clin Cancer Res. 2016;22(12): 2848-54.

Hingorani SR, Zheng L, Bullock AJ, Seery TE, Harris WP, Sigal DS, et al. HALO 202: randomized phase II study of PEGPH20 plus nab-paclitaxel/gemcitabine versus nab-paclitaxel/gemcitabine in patients with untreated, metastatic pancreatic ductal adenocarcinoma. J Clin Oncol. 2018:359-66.

Hirakawa T, Yashiro M, Doi Y, Kinoshita H, Morisaki T, Fukuoka T, et al. Pancreatic fibroblasts stimulate the motility of pancreatic cancer cells through IGF1/IGF1R signaling under hypoxia. PLoS One. 2016;11(8):1-14.

Hirata E, Girotti MR, Viros A, Hooper S, Spencer-Dene B, Matsuda $\mathrm{M}$, et al. Intravital imaging reveals how BRAF inhibition generates drug-tolerant microenvironments with high integrin $\beta 1 /$ FAK signaling. Cancer Cell. 2015;27(4): 574-88.

Hu M, Yao J, Cai L, Bachman KE, van den Brûle F, Velculescu V, et al. Distinct epigenetic changes in the stromal cells of breast cancers. Nat Genet. 2005;37(8):899-905.

Ikenaga N, Ohuchida K, Mizumoto K, Cui L, Kayashima T, Morimatsu K, et al. CD10+ pancreatic stellate cells enhance the progression of pancreatic cancer. Gastroenterology. 2010;139(3):1041-1051.e8 Available from: https://doi. org/10.1053/j.gastro.2010.05.084.

Jacobetz MA, Chan DS, Neesse A, Bapiro TE, Cook N, Frese KK, et al. Hyaluronan impairs vascular function and drug delivery in a mouse model of pancreatic cancer. Gut. 2013;62:112-20.

Jaster R. Molecular regulation of pancreatic stellate cell function. Mol Cancer. 2004;3(26):26.

Jayson GC, Kerbel R, Ellis LM, Harris AL. Antiangiogenic therapy in oncology: current status and future directions. Lancet (London, England). 2016;388(10043):518-29.

Jeon ES, Moon HJ, Lee MJ, Song HY, Kim YM, Cho M, et al. Cancer-derived lysophosphatidic acid stimulates differentiation of human mesenchymal stem cells to myofibroblast-like cells. Stem Cells. 2008;26(3):789-97.

Jiang L, Gonda TA, Gamble MV, Salas M, Seshan V, Tu S, et al. Global hypomethylation of genomic DNA in cancerassociated myofibroblasts. Cancer Res. 2008;68(23):9900-8.

Johansson A-C, Ansell A, Jerhammar F, Lindh MB, Grenman R, Munck-Wikland E, et al. Cancer-associated fibroblasts induce matrix metalloproteinase-mediated Cetuximab resistance in head and neck squamous cell carcinoma cells. Mol Cancer Res. 2012;10(9):1158-68.

Kalluri R. Angiogenesis: basement membranes: structure, assembly and role in tumour angiogenesis. Nat Rev Cancer. 2003;3(6):422-33.

Kalluri R, Neilson EG. Epithelial-mesenchymal transition and its implications for fibrosis. J Clin Investig. 2003;112:1776-84.

Kalluri R, Zeisberg M. Fibroblasts in cancer. Nat Rev Cancer. 2006;6(5):392-401. 
Kanno A, Satoh K, Masamune A, Hirota M, Kimura K, Umino J, et al. Periostin, secreted from stromal cells, has biphasic effect on cell migration and correlates with the epithelial to mesenchymal transition of human pancreatic cancer cells. Int J Cancer. 2008;122(12):2707-18.

Kerbel RS. A cancer therapy resistant to resistance. Nature. 1997;390(6658):335-6.

Khokha R, Murthy A, Weiss A. Metalloproteinases and their natural inhibitors in inflammation and immunity. Nat Rev Immunol. 2013;13(9):649-65.

Kojima Y, Acar A, Eaton EN, Mellody KT, Scheel C, Ben-Porath I, et al. Autocrine TGF-beta and stromal cell-derived factor-1 (SDF-1) signaling drives the evolution of tumor-promoting mammary stromal myofibroblasts. Proc Natl Acad Sci U S A. 2010;107(46):20009-14.

Koliaraki V, Pasparakis M, Kollias G. IKK $\beta$ in intestinal mesenchymal cells promotes initiation of colitis-associated cancer. J Exp Med. 2015;212(13):2235-51.

Kraman M, Bambrough PJ, Arnold JN, Roberts EW, Magiera L, Jones JO, et al. Suppression of antitumor immunity by stromal cells expressing fibroblast activation protein-a Matthew. Science (80- ). 2010;330(November):827-30.

Kugeratski FG, Hernandez JR, Kalna G, Zanivan S. Abstract A34: hypoxic cancer-associated fibroblasts secrete regulators of angiogenesis: novel potential players revealed by MS. Cancer Res. 2016;76(15 Supplement):A34 LP-A34 Available from: http://cancerres.aacrjournals.org/content/76 /15_Supplement/A34.abstract.

Kultti A, Zhao C, Zimmerman S, Osgood RJ, Chen Y, Symons R, et al. Extracellular hyaluronan accumulation by hyaluronan synthase 3 promotes pancreatic cancer growth and modulates tumor microenvironment via epithelial-mesenchymal transition. Cancer Res. 2014;74(19) Available from: http://cancerres.aacrjournals.org/lookup/doi/10.1158/15387445.AM2014-4844.

Kuninty PR, Bojmar L, Tjomsland V, Larsson M, Storm G, Östman A, et al. MicroRNA-199a and -214 as potential therapeutic targets in pancreatic stellate cells in pancreatic tumor. Oncotarget. 2016;7(13):16396-408.

Li H, Fan X, Houghton J. Tumor microenvironment: the role of the tumor stroma in cancer. J Cell Biochem. 2007;101(4): $805-15$.

Liu J, Liao S, Diop-Frimpong B, Chen W, Goel S, Naxerova K, et al. TGF- blockade improves the distribution and efficacy of therapeutics in breast carcinoma by normalizing the tumor stroma. Proc Natl Acad Sci. 2012;109(41):16618-23.

Lotti F, Jarrar AM, Pai RK, Hitomi M, Lathia J, Mace A, et al. Chemotherapy activates cancer-associated fibroblasts to maintain colorectal cancer-initiating cells by IL-17A. J Exp Med. 2013;210(13):2851-72.

MacE TA, Shakya R, Pitarresi JR, Swanson B, McQuinn CW, Loftus S, et al. IL-6 and PD-L1 antibody blockade combination therapy reduces tumour progression in murine models of pancreatic cancer. Gut. 2018;67(2):320-32.

Madsen CD, Pedersen JT, Venning FA, Singh LB, Charras G, Cox TR, et al. Hypoxia and loss of PHD 2 inactivate stromal fibroblasts to decrease tumour stiffness and metastasis. EMBO Rep. 2015;16(10):1394-408.

Malanchi I, Santamaria-Martinez A, Susanto E, Peng H, Lehr HA, Delaloye J-F, et al. Abstract SY28-02: Interactions between cancer stem cells and their niche govern metastatic colonization. Cancer Res. 2012;72(8 Supplement):SY28-02SY28-02.

Mao Y, Keller ET, Garfield DH, Shen K, Wang J. Stroma cells in tumor microenvironment and breast Cancer. Cancer Metastasis Rev. 2013;32(0):303-15.

Martinez-outschoorn UE, Goldberg A, Lin Z, Ko Y, Flomenberg $\mathrm{N}$, Wang $\mathrm{C}$, et al. Anti-estrogen resistance in breast cacner is induced by the tumor microenvironment and can be overcome by inhibiting mitochondrial function in epithelial cancer cells. Cancer Biol Ther. 2011;12(10):924-38.

Masamune A, Kikuta K, Watanabe T, Satoh K, Hirota M, Shimosegawa T. Hypoxia stimulates pancreatic stellate cells to induce fibrosis and angiogenesis in pancreatic cancer. Am J Physiol Liver Physiol. 2008;295(4):G709-17 Available from: http://www.physiology.org/doi/10.1152 /ajpgi.90356.2008.

Mathot P, Grandin M, Devailly G, Souaze F, Cahais V, Moran S, et al. DNA methylation signal has a major role in the response of human breast cancer cells to the microenvironment. Oncogenesis. 2017;6(10):e390 Available from: http://www. nature.com/doifinder/10.1038/oncsis.2017.88.

McCarroll JA, Phillips PA, Santucci N, Pirola RC, Wilson JS, Apte MV. Vitamin a inhibits pancreatic stellate cell activation: implications for treatment of pancreatic fibrosis. Gut. 2006;55(1):79-89.

McMillin DW, Delmore J, Weisberg E, Negri JM, Geer DC, Klippel S, et al. Tumor cell-specific bioluminescence platform to identify stroma-induced changes to anticancer drug activity. Nat Med. 2010;16(4):483-9.

Meads MB, Gatenby RA, Dalton WS. Environment-mediated drug resistance: a major contributor to minimal residual disease. Nat Rev Cancer. 2009;9(9):665-74.

Melanie A, Simpson VBL. Hyaluronan and hyaluronidase in genitourinary tumors. Front Biosci. 2008;13:5664-80.

Mishra PJ, Mishra PJ, Humeniuk R, Medina DJ, Alexe G, Mesirov JP, et al. Carcinoma-associated fibroblast-like differentiation of human mesenchymal stem cells. Cancer Res. 2008;68(11): 4331-9.

Misra S, Obeid LM, Hannun YA, Minamisawa S, Berger FG, Markwald RR, et al. Hyaluronan constitutively regulates activation of COX-2-mediated cell survival activity in intestinal epithelial and colon carcinoma cells. J Biol Chem. 2008;283(21):14335-44.

Moffitt RA, Marayati R, Flate EL, Volmar KE, Loeza SGH, Hoadley KA, et al. Virtual microdissection identifies distinct tumor- and stroma-specific subtypes of pancreatic ductal adenocarcinoma. Nat Genet. 2015;47(10):1168-78 Available from: https://doi.org/10.1038/ng.3398.

Mueller MM, Fusenig NE. Friends or foes - bipolar effects of the tumour stroma in cancer. Nat Rev Cancer. 2004;4(11): 839-49.

Multhaupt HAB, Leitinger B, Gullberg D, Couchman JR. Extracellular matrix component signaling in cancer. Adv Drug Deliv Rev. 2016;97:28-40.

Nakasone ES, Askautrud HA, Kees T, Park JH, Plaks V, Ewald $\mathrm{AJ}$, et al. Imaging tumor-stroma interactions during chemotherapy reveals contributions of the microenvironment to resistance. Cancer Cell. 2012;21(4):488-503.

Öhlund D, Handly-Santana A, Biffi G, Elyada E, Almeida AS, Ponz-Sarvise M, et al. Distinct populations of inflammatory fibroblasts and myofibroblasts in pancreatic cancer. J Exp 
Med. 2017;jem.20162024. Available from: http://www.jem. org/lookup/doi/10.1084/jem.20162024

Olive KP, Jacobetz MA, Davidson CJ, Gopinathan A, McIntyre D, Honess D, et al. Inhibition of Hedgehog signaling enhances delivery of chemotherapy in a mouse model of pancreatic cancer. Science (80- ). 2009;324(5933):1457-61.

Olive KP, Jacobetz MA, Davidson CJ, Mcintyre D, Honess D, Madhu B, et al. Chemotherapy in a mouse model of pancreatic Cancer. Cancer Res. 2010;324(5933):1457-61.

Orimo A, Weinberg RA. Stromal fibroblasts in cancer: a novel tumor-promoting cell type. Cell Cycle. 2006;5:1597-601.

Orimo A, Gupta PB, Sgroi DC, Arenzana-Seisdedos F, Delaunay $\mathrm{T}$, Naeem R, et al. Stromal fibroblasts present in invasive human breast carcinomas promote tumor growth and angiogenesis through elevated SDF-1/CXCL12 secretion. Cell. 2005;121(3):335-48.

Östman A, Heldin CH. PDGF receptors as targets in tumor treatment. Adv Cancer Res. 2007;97:247-74.

Ostrand-Rosenberg S. Immune surveillance: a balance between protumor and antitumor immunity. Curr Opin Genet Dev. 2008;18:11-8.

Özdemir BC, Pentcheva-Hoang T, Carstens JL, Zheng X, Wu CC, Simpson TR, et al. Depletion of carcinoma-associated fibroblasts and fibrosis induces immunosuppression and accelerates pancreas cancer with reduced survival. Cancer Cell. 2014;25(6):719-34.

Paggetti J, Haderk F, Seiffert M, Janji B, Distler U, Ammerlaan W, et al. Exosomes released by chronic lymphocytic leukemia cells induce the transition of stromal cells into cancerassociated fibroblasts. Blood. 2015;126(9):1106-17.

Pallangyo CK, Ziegler PK, Greten FR. IKK $\beta$ acts as a tumor suppressor in cancer-associated fibroblasts during intestinal tumorigenesis. J Exp Med. 2015;212(13):2253-66.

Palucka AK, Coussens LM. The basis of oncoimmunology. Cell. 2016;164:1233-47.

Paraiso KHT, Smalley KSM. Fibroblast-mediated drug resistance in cancer. Biochem Pharmacol. 2013;85:1033-41.

Park H, Lee Y, Lee H, Kim JW, Hwang JH, Kim J, et al. The prognostic significance of cancer-associated fibroblasts in pancreatic ductal adenocarcinoma. Tumor Biol. 2017;39(10):1-9.

Pietras K, Sjöblom T, Rubin K, Heldin C-H, Ostman A. PDGF receptors as cancer drug targets. Cancer Cell. 2003;3(5): 439-43.

Pistore C, Giannoni E, Colangelo T, Rizzo F, Magnani E, Muccillo $\mathrm{L}$, et al. DNA methylation variations are required for epithelial-to-mesenchymal transition induced by cancerassociated fibroblasts in prostate cancer cells. Oncogene. 2017;36(40):5551-66.

Pontiggia O, Sampayo R, Raffo D, Motter A, Xu R, Bissell MJ, et al. The tumor microenvironment modulates tamoxifen resistance in breast cancer: a role for soluble stromal factors and fibronectin through ??1 integrin. Breast Cancer Res Treat. 2012;133(2):459-71.

Prakash J. Cancer-associated fibroblasts: perspectives in Cancer therapy. Trends Cancer. 2016;2(6):277-9.

Provenzano PP, Cuevas C, Chang AE, Goel VK, Von Hoff DD, SRH. Enzymatic targeting of the stroma ablates physical barriers to treatment of pancreatic ductal adenocarcinoma. Cancer Cell. 2012;21(3):418-29.
Quail DF, Joyce JA. Microenvironmental regulation of tumor progression and metastasis. Nat Med. 2013;19(11):1423-37.

Quante M, Tu SP, Tomita H, Gonda T, Wang SSW, Takashi S, et al. Bone marrow-derived Myofibroblasts contribute to the mesenchymal stem cell niche and promote tumor growth. Cancer Cell. 2011;19(2):257-72.

Rhim AD, Oberstein PE, Thomas DH, Mirek ET, Palermo CF, Sastra SA, et al. Stromal elements act to restrain, rather than support, pancreatic ductal adenocarcinoma. Cancer Cell. 2014;25(6):735-47.

Sanz-Moreno V, Gaggioli C, Yeo M, Albrengues J, Wallberg F, Viros A, et al. ROCK and JAK1 signaling cooperate to control Actomyosin contractility in tumor cells and stroma. Cancer Cell. 2011;20(2):229-45.

Sato N, Cheng XB, Kohi S, Koga A, Hirata K. Targeting hyaluronan for the treatment of pancreatic ductal adenocarcinoma. Acta Pharm Sin B. 2016;6(2):101-5 Available from: https://doi.org/10.1016/j.apsb.2016.01.002.

Shao ZM, Nguyen M, Barsky SH. Human breast carcinoma desmoplasia is PDGF initiated. Oncogene. 2000;19(38): 4337-45.

Shekhar MPV, Santner S, Carolin K. A, Tait L. direct involvement of breast tumor fibroblasts in the modulation of tamoxifen sensitivity. Am J Pathol. 2007;170(5):1546-60.

Shimoda M, Mellody KT, Orimo A. Carcinoma-associated fibroblasts are a rate-limiting determinant for tumour progression. Semin Cell Dev Biol. 2010;21:19-25.

Shin K, Lim A, Zhao C, Sahoo D, Pan Y, Spiekerkoetter E, et al. Hedgehog signaling restrains bladder cancer progression by eliciting stromal production of urothelial differentiation factors. Cancer Cell. 2014;26(4):521-33.

Sonnenberg M, van der Kuip H, Haubeis S, Fritz P, Schroth W, Friedel G, et al. Highly variable response to cytotoxic chemotherapy in carcinoma-associated fibroblasts (CAFs) from lung and breast. BMC Cancer. 2008;8(1):364.

Spaeth EL, Dembinski JL, Sasser AK, Watson K, Klopp A, Hall $\mathrm{B}$, et al. Mesenchymal stem cell transition to tumorassociated fibroblasts contributes to fibrovascular network expansion and tumor progression. PLoS One. 2009;4(4).

Straussman R, Morikawa T, Shee K, Barzily-Rokni M, Qian ZR, $\mathrm{Du}$ J, et al. Tumour micro-environment elicits innate resistance to RAF inhibitors through HGF secretion. Nature. 2012;487(7408):500-4.

Strutz F, Okada H, Lo CW, Danoff T, Carone RL, Tomaszewski $\mathrm{JE}$, et al. Identification and characterization of a fibroblast marker: FSP1. J Cell Biol. 1995;130(2):393-405.

Sugimoto H, Mundel TM, Kieran MW, Kalluri R. Identification of fibroblast heterogeneity in the tumor microenvironment. Cancer Biol Ther. 2006;5(12):1640-6.

Sun Y, Campisi J, Higano C, Beer TM, Porter P, Coleman I, et al. Treatment-induced damage to the tumor microenvironment promotes prostate cancer therapy resistance through WNT16B. Nat Med. 2012;18(9):1359-68.

Sun Y, Zhu D, Chen F, Qian M, Wei H, Chen W, et al. SFRP2 augments WNT16B signaling to promote therapeutic resistance in the damaged tumor microenvironment. Oncogene. 2016;35(33):4321-34.

Tian X, Azpurua J, Hine C, Vaidya A, Myakishev-Rempel M, Ablaeva $\mathrm{J}$, et al. High-molecular-mass hyaluronan mediates the cancer resistance of the naked mole rat. Nature. 
2013;499(7458):346-9 Available from: https://doi. org/10.1038/nature12234.

Tian X, Azpurua J, Ke Z, Augereau A, Zhang ZD, Vijg J, et al. INK4 locus of the tumor-resistant rodent, the naked mole rat, expresses a functional p15/p16 hybrid isoform. Proc Natl Acad Sci. 2015;112(4):1053-8 Available from: http://www. pnas.org/lookup/doi/10.1073/pnas.1418203112.

Tlsty TD, Coussens LM. Tumor stroma and regulation of Cancer development. Annu Rev Pathol Mech Dis. 2006;1(1):119-50.

Triggs-Raine B. Biology of hyaluronan: Insights from genetic disorders of hyaluronan metabolism. World J Biol Chem. 2015;6(3):110 Available from: http://www.wjgnet. com/1949-8454/full/v6/i3/110.htm.

Turley EA, Wood DK, McCarthy JB. Carcinoma cell hyaluronan as a "portable" cancerized prometastatic microenvironment. Cancer Res. 2016;76(9):2507-12.

Tyan SW, Hsu CH, Peng KL, Chen CC, Kuo WH, Lee EYHP, et al. Breast cancer cells induce stromal fibroblasts to secrete ADAMTS1 for cancer invasion through an epigenetic change. PLoS One. 2012;7(4).

Valencia T, Kim JY, Abu-Baker S, Moscat-Pardos J, Ahn CS, Reina-Campos M, et al. Metabolic reprogramming of stromal fibroblasts through p62-mTORC1 signaling promotes inflammation and tumorigenesis. Cancer Cell. 2014;26(1): 121-35.

Von Hoff DD, Ervin T, Arena FP, Chiorean EG, Infante J, Moore $\mathrm{M}$, et al. Increased survival in pancreatic Cancer with nabpaclitaxel plus gemcitabine. N Engl J Med. 2013;369(18): 1691-703 Available from: http://www.nejm.org/doi/10.1056 /NEJMoa1304369.

Vukovic V, Tannock IF. Influence of low $\mathrm{pH}$ on cytotoxicity of paclitaxel, mitoxantrone and topotecan. $\mathrm{Br} \mathrm{J}$ Cancer. 1997;75(8):1167-72.

Wagner EF. Cancer: fibroblasts for all seasons. Nature. 2016;530(7588):42-3.

Wang W, Li Q, Yamada T, Matsumoto K, Matsumoto I, Oda M, et al. Crosstalk to stromal fibroblasts induces resistance of lung cancer to epidermal growth factor receptor tyrosine kinase inhibitors. Clin Cancer Res. 2009;15(21):6630-8.

Wartenberg M, Ling FC, Müschen M, Klein F, Acker H, Gassmann M, et al. Regulation of the multidrug resistance transporter P-glycoprotein in multicellular tumor spheroids by hypoxia-inducible factor (HIF-1) and reactive oxygen species. FASEB J. 2003;17(3):503-5.

Webber J, Spary L, Sanders A, Chowdhury R, Jiang W, Steadman $\mathrm{R}$, et al. Differentiation of tumour-promoting stromal myofibroblasts by cancer exosomes. Oncogene. 2015;34(3): 319-31.

Wilson WR, Hay MP. Targeting hypoxia in cancer therapy. Nat Rev Cancer. 2011;11(6):393-410.

Wilson TR, Fridlyand J, Yan Y, Penuel E, Burton L, Chan E, et al. Widespread potential for growth-factor-driven resistance to anticancer kinase inhibitors. Nature. 2012;487(7408):505-9.

Wong KM, Horton KJ, Coveler AL, Hingorani SR, Harris WP. Targeting the tumor stroma: the biology and clinical development of pegylated recombinant human hyaluronidase (PEGPH20). Curr Oncol Rep. 2017;19(7).

Wörmann SM, Song L, Ai J, Diakopoulos KN, Kurkowski MU, Görgülü K, et al. Loss of P53 Function Activates JAK2STAT3 Signaling to Promote Pancreatic Tumor Growth, Stroma Modification, and Gemcitabine Resistance in Mice and Is Associated With Patient Survival. Gastroenterology. 2016;151(1):180-193.e12 Available from: https://doi. org/10.1053/j.gastro.2016.03.010.

Wu RL, Huang L, Zhao HC, Geng XP. Hyaluronic acid in digestive cancers. J Cancer Res Clin Oncol. 2017;143(1) Available from: "https://doi.org/10.1007/s00432-016-2213-5.

Xiao G-H, Jeffers M, Bellacosa A, Mitsuuchi Y, Vande Woude GF, Testa JR. Anti-apoptotic signaling by hepatocyte growth factor/Met via the phosphatidylinositol 3-kinase/Akt and mitogen-activated protein kinase pathways. Proc Natl Acad Sci U S A. 2001;98(1):247-52.

Yin C, Evason K. Hepatic stellate cells in liver development, regeneration, and cancer. J Clin Investig. 2013;123(5): 1902-10.

Zeisberg EM, Potenta S, Xie L, Zeisberg M, Kalluri R. Discovery of endothelial to mesenchymal transition as a source for carcinoma-associated fibroblasts. Cancer Res. 2007;67(21): 10123-8.

Zeltz C, Gullberg D. The integrin-collagen connection - a glue for tissue repair? J Cell Sci. 2016;129(6):653-64.

Zhang L, Huang G, Li X, Zhang Y, Jiang Y, Shen J, et al. Hypoxia induces epithelial-mesenchymal transition via activation of SNAI1 by hypoxia-inducible factor $-1 \alpha$ in hepatocellular carcinoma. BMC Cancer. 2013;13:24-7. 